\title{
Rancang Bangun Sistem Informasi Penggajian Karyawan Menggunakan Metode Fuzzy Tsukamoto
}

\author{
Dickypradana Abdulrahman Julianto $^{* 1}$, Septi Andryana ${ }^{2}$ dan Aris Gunaryati ${ }^{3}$ \\ ${ }^{1,2,3}$ Universitas Nasional; Jl. Sawo Manila, Pejaten Ps. Minggu Jakarta 12520 \\ ${ }^{1,2,3}$ Fakutas Teknologi Komunikasi dan Informatika Universitas Nasional \\ e-mail: *1dickypradana17aj@gmail.com, ${ }^{2}$ septi.andryan@civitas.unas.ac.id, \\ 3aris.gunaryati@civitas.unas.ac.id
}

\begin{abstract}
Abstrak
Apresiasi terhadap kinerja karyawan sangat diperlukan di suatu perusahaan untuk meningkatkan mutu kinerja serta semangat bekerja bagi karyawan. Salah satunya PT. Olew Plasindo Jaya Makmur bergerak dibidang distributor kemasan kosmetik. perusahaan ini memberikan apresiasi berbentuk bonus pada karyawannya. Perhitungan bonus yang ada menggunakan beberapa kriteria seperti masa kerja karyawan dan gaji bersih karyawan. Dari kriteria yang diperoleh dapat dihitung menggunakan metode Fuzzy Tsukamoto, kemudian menciptakan keputusan berbentuk variabel sedikit dan banyak. Setelah keputusan variabel didapatkan akan menghasilkan nominal bonus karyawan. Adapun perhitungan setiap variabel berada dalam sebuah sistem informasi penggajian karyawan yang disebut SIPEKA.
\end{abstract}

Kata kunci: Bonus Gaji, Fuzzy Tsukamoto, Sistem Informasi Penggajian Karyawan

\begin{abstract}
Appreciation of employee performance is needed in a company to improve the quality of performance and enthusiasm for work for employees. One of them is PT. Olew Plasindo Jaya Makmur is engaged in cosmetic packaging distributors. This company gives appreciation in the form of bonuses to its employees. The calculation of the existing bonuses uses several criteria such as the employee's tenure and the employee's net salary. From the criteria obtained, it can be calculated using the Tsukamoto method, then creating decisions in the form of few and many variables. After the variable decision is obtained, it will produce a nominal employee bonus. The calculation of each variable is in an employee payroll information system called SIPEKA.
\end{abstract}

Keywords: Salary Bonus, Fuzzy Tsukamoto, Employee Payroll Information System

\section{PENDAHULUAN}

Sistem informasi digunakan untuk pengelolaan data dalam proses bisnis. Data yang dibutuhkan dalam proses bisnis secara otomatis dikelola dan diproses oleh sistem, sehingga menjadi informasi yang dibutuhkan pengguna. Sistem informasi dibuat untuk membuat berbagai proses manual menjadi terkomputerisasi, sehingga lebih efektif dan efisien, sehingga mencegah duplikasi data atau kesalahan penyajian kembali data. Memiliki sistem informasi penggajian yang benar menjadi solusi bagi instansi agar tidak terjadi kesalahan dalam proses penggajian dari awal sampai akhir, karena dilakukan secara sistematis, sehingga setiap pegawai dibayar sesuai hak masing-masing pegawai[1].

PT. Olew Plasindo Jaya Makmur merupakan perusahaan bergerak dibidang distributor kemasan kosmetik dan telah memiliki hampir 100 karyawan yang bekerja, dengan pembagian divisi yang berbeda beda, dalam proses penggajian karyawan masih tergolong dijalankan secara 
konvensional mulai dari perekapan data yang dibutuhkan sampai proses penggajian serta pemberian bonus gaji untuk karyawan.

Demi memotivasi semangat kerja karyawan, maka pimpinan perusahaan membuat ketentuan sebuah apresiasi berupa bonus pada setiap karyawan yang dikeluarkan bersamaan dengan gaji karyawan[2]. Kriteria dalam penentuan bonus gaji karyawan PT.Olew Plasindo Jaya Makmur berdasarkan masa kerja karyawan dan gaji bersih karyawan. Dari data kriteriakriteria yang ada selanjutnya dikalkulasi dengan sebuah metode yaitu Fuzzy Tsukamoto. Hasil yang diharapkan adalah sebuah variabel sedikit atau banyak kemudian menampilkan nominal bonus yang diperoleh berupa nominal dalam mata uang rupiah. Untuk membangun sistem informasi tersebut menggunakan MYSQL dan PHP.

Penelitian terdahulu yang pernah dilakukan oleh Achmad Zaki[3] terkait metode fuzzy Tsukamoto untuk mengetahui kondisi energi di Indonesia masuk kedalam klasifikasi aman, waspada, atau krisis. Penelitian ini mampu memisahkan permasalahan kekurangan energi seperti minyak bumi, gas alam dan batubara dengan menggunakan kriteria-kriteria seperti produksi, konsumsi, GDP dan penduduk.

Selanjutnya penelitian yang pernah dilakukan oleh Rifki Setya Armanda[4] untuk meramalkan permintaan barang dengan data primer Koperasi Semen Gresik (KWSG) dengan menggunakan 4 kriteria, yaitu T3 untuk permintaan 3 minggu sebelumnya, T2 untuk permintaan 2 minggu sebelumnya, T1 untuk permintaan 1minggu sebelumnya, dan $\mathrm{T}$ untuk permintaan barang minggu selanjutnya.

Kemudian penelitian yang pernah dilakukan oleh Mutiara Santa [5] untuk mengevaluasi kualitas layanan digunakan lima dimensi karakteristik, dari karakteristik tersebut dibagi lagi menjadi subkriteria masing-masing.

Berdasarkan latar belakang tersebut, maka penulis memutuskan judul penelitian yaitu

"Rancang Bangun Sistem Informasi Penggajian Karyawan Menggunakan Metode Fuzzy Tsukamoto".

\section{METODE PENELITIAN}

Metode penelitian yang digunakan dalam pembuatan penelitian ini adalah Metode Pengumpulan Data, Rancangan, Pengujian dan Penerapan Sistem.

\subsection{Analisis Sistem}

Tahapan penelitian ini dilakukan akumulasi data melalui wawancara dengan pimpinan PT. Olew Plasindo Jaya Makmur, kemudian menggunakan pengamatan langsung atau observasi untuk memastikan kondisi masalah yang akan diteliti serta melakukan studi pustaka untuk memperdalam pemahaman penyelesaian masalah yang ada. Untuk data yang diperoleh berupa data primer dan data sekunder yang digunakan sebagai sumber data. Analisa yang dilakukan peneliti antara lain:

1. Akumulasi Data

Peneliti menggunakan 3 cara yaitu wawancara, observasi, dan studi pustaka dalam mengumpulkan data, yaitu:

a. Wawancara

Pengumpulan data yang diperoleh dengan cara mengajukan pertanyaan terkait kriteria yang digunakan untuk menentukan bonus gaji karyawan.

b. Observasi

Terjun langsung ke PT. Olew Plasindo Jaya Makmur. Dengan cara ini agar memperoleh data karyawan yang akurat dan rill. Dalam pengamatan secara langsung ini mempunyai keunggulan, yaitu untuk mendapatkan informasi terkait tujuan prediksi bonus gaji karyawan berdasarkan ketetapan kriteria yang diperoleh. 
c. Studi Pustaka

Informasi ini didapatkan dari sumber-sumber terkait dengan rumusan masalah yang diteliti. Dalam mengakuratkan analisis, dilakukan pula kegiatan lain oleh penulis seperti membaca artikel, jurnal ilmiah dan studi literatur lain di perpustakaan.

2. Sumber Data

Data yang diperoleh dari hasil pengumpulan data kemudian akan dianalisis dengan membagi sesuai jenis informasi, sesuai dengan manajemen data yaitu data primer atau data sekunder.

a. Data Primer

Untuk jenis data karyawan dan cara pemberian bonus gaji karyawan termasuk kedalam jenis data primer.

b. Data Sekunder

Data yang berasal dari tinjauan pustaka, yang terdiri dari jurnal penelitian, buku, internet, artikel dan sumber data lainnya termasuk dalam data sekunder.

\section{2 Pengujian Sistem}

Pengujian sistem yang dilakukan adalah mulai dari proses memasukkan data yang ada hingga menutup sistem, kemudian melihat keakuratan data-data yang dihitung dibandingkan secara manual dan rill, untuk melihat presentase keakuratan sistem.

\section{3 Implementasi Sistem}

Membentuk sistem yang dapat mengoptimalkan kerja, mulai dari tahap awal hingga pengujian sistem yang ada. Penggunaan PHP sebagai bahasa pemograman dalam membangun sistem ini, sehingga sistem yang dibuat adalah aplikasi web dengan menggunakan database MYSQL. Aplikasi desktop terpilih adalah XAMPP untuk menjadi virtual server.

\section{4 Logika Fuzzy}

Logika fuzzy dapat mensimulasikan keahlian berpikir manusia dalam wujud algoritma, serta setelah itu dioperasikan pada mesin. Berbagai macam aplikasi pengolahan informasi yang sulit diperkirakan dalam wujud biner menggunakan algoritma ini. Logika fuzzy menafsirkan statment fuzzy dengan arti yang logis. Sistem fuzzy berbasis ketentuan( pengetahuan). seperangkat ketentuan IF- THEN yang membentuk sistem ini.. Contoh: jika mobil ingin melaju dengan cepat, maka tambahkan daya putar mesin dengan cara gas mesin mobil dinaikan seiring dengan perseneling mobil ditingkatkan [6].

\section{5 Fuzzy Tsukamoto}

Dalam tata cara metode Tsukamoto, tiap ketentuan pakai representasi anggota fuzzy, menggunakan keanggotaan yang sama. Tentukan nilai keluaran, carilah kesimpulan yang pasti ataupun konstan dengan mengganti input( dalam wujud himpunan fuzzy diperoleh dari campuran ketentuan fuzzy). Apakah angka di bidang yang diresmikan berbeda, tata cara ini diucap tata cara defuzzifikasi(pasti). Tata cara defuzzifikasi digunakan dalam hukum fuzzy Tsukamoto merupakan tata cara defuzzifikasi rata- rata terpusat [7]. 
Aturan $\mathrm{Ke}-1$

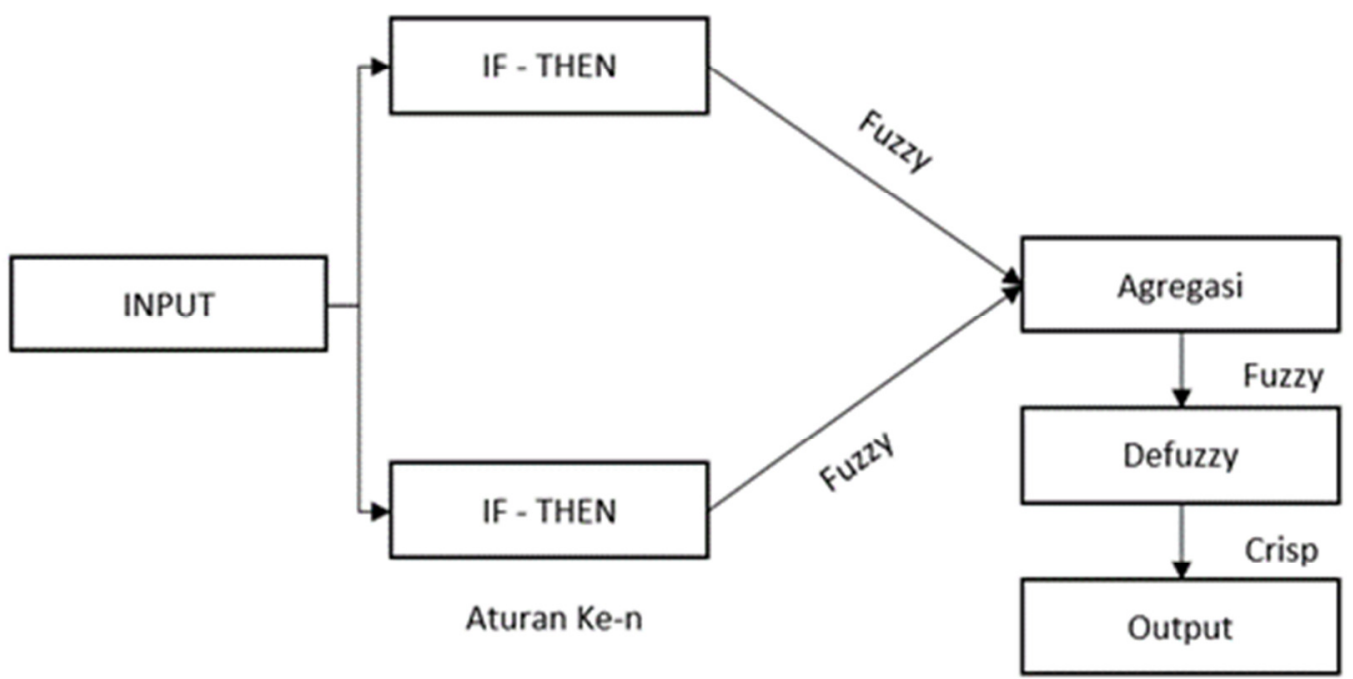

Gambar 1. Diagram Blok Sistem Inferensi Fuzzy

Tahapan pengerjaan menggunakan metode fuzzy Tsukamoto:

1. Menetapkan faktor fuzzy yang memiliki nilai masukan dan nilai keluaran yang disebut fuzzifikasi.

2. Inferensi fuzzy yaitu membentuk susunan fuzzy atau mesin perhitungan inferensi fuzzy. Gambar 2 menerangkan proses inferensi fuzzy Tsukamoto.
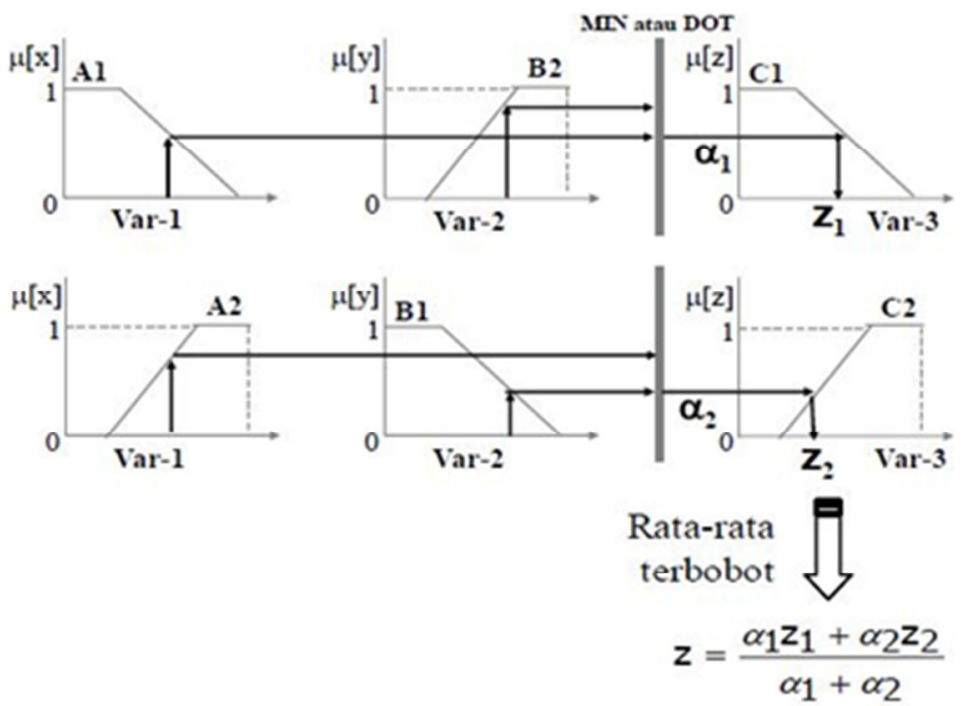

Gambar 2. Inferensi Fuzzy Tsukamoto

3. Defuzzyfikasi adalah proses penerapan nilai rata-rata terbobot dalam menemukan nilai keluaran crips. 


\section{HASIL DAN PEMBAHASAN}

\subsection{Proses Fuzzifikasi}

Proses fuzzifikasi pada penelitian ini menggunakan beberapa kriteria dalam menentukan bonus gaji, untuk masa kerja dan gaji bersih karyawan masuk kedalam nilai masukan. Sedangkan untuk nilai keluaran pada proses ini adalah berupa bonus gaji.

a. Nilai Masukan

Nilai masukan yang digunakan adalah beberapa kriteria yang menguatkan. Pada rumusan masalah penelitian ini terdapat 2 kriteria yaitu masa kerja karyawan terdiri dari derajat keanggotaan Baru, Sedang, dan Lama sedangkan gaji bersih karyawan terdiri dari derajat keanggotaan Sedikit dan Banyak.

b. Nilai Keluaran

Nilai keluaran yang diharapkan untuk mencapai tujuan penelitian ini adalah bonus gaji dimana hasil bonus gaji diperoleh menggunakan nilai masukan berupa kriteria-kriteria yang telah ditetapkan, dengan derajat keanggotaan Sedikit dan Banyak.

Respresentasi fuzzifikasi dari masing-masing variabel input menggunakan kurva untuk menentukan derajat keanggotaan adalah sebagai berikut:

a. Fuzzifikasi variabel masa kerja yang didapatkan dari kurva pada gambar 3 berikut.

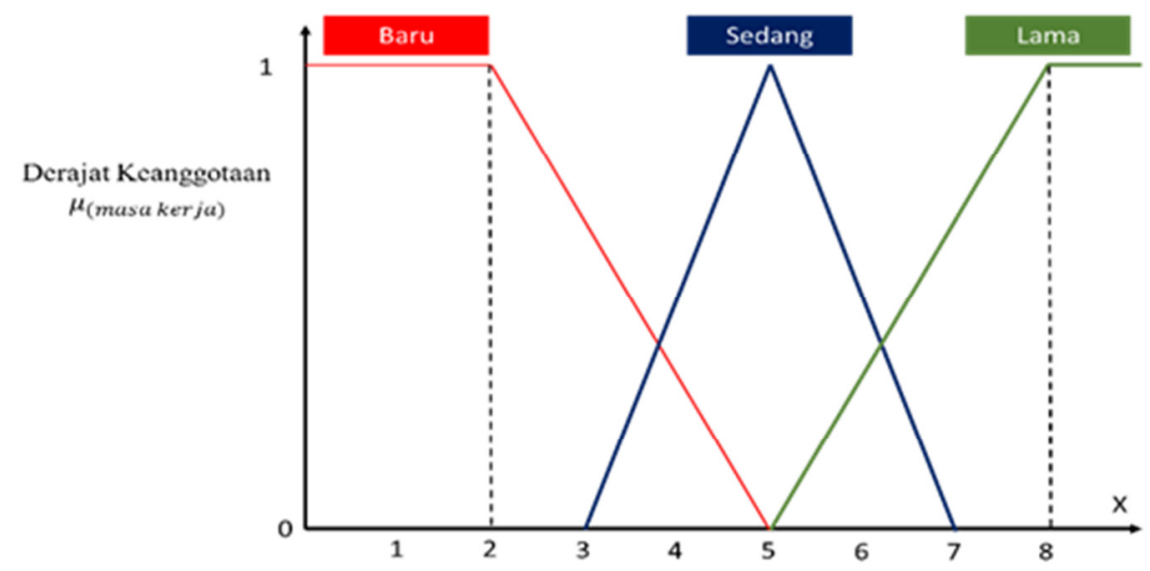

Gambar 3. Kurva Masa Kerja

$$
\begin{gathered}
\left.\mu_{\text {baru }} \text { (masa kerja }\right)=\left\{\begin{array}{cc}
0, & x \geq 5 \\
\frac{5-x}{3}, & 2<x<5 \\
1, & x \leq 2
\end{array}\right. \\
\mu_{\text {sedang }} \quad \text { (masa kerja) }=\left\{\begin{array}{cc}
0, & x \leq 3 \text { atau } x \geq 7 \\
\frac{1,}{2}, & 3<x<5 \\
\frac{7-x}{2}, & 5<x<7
\end{array}\right.
\end{gathered}
$$




$$
\mu_{\text {lama }}(\text { masa kerja })=\left\{\begin{array}{cc}
0, & x \leq 5 \\
\frac{x-5}{3}, & 5<x<8 \\
1, & x \geq 8
\end{array}\right.
$$

b. Fuzzifikasi variabel gaji bersih yang didapatkan dari kurva pada gambar 4 berikut.

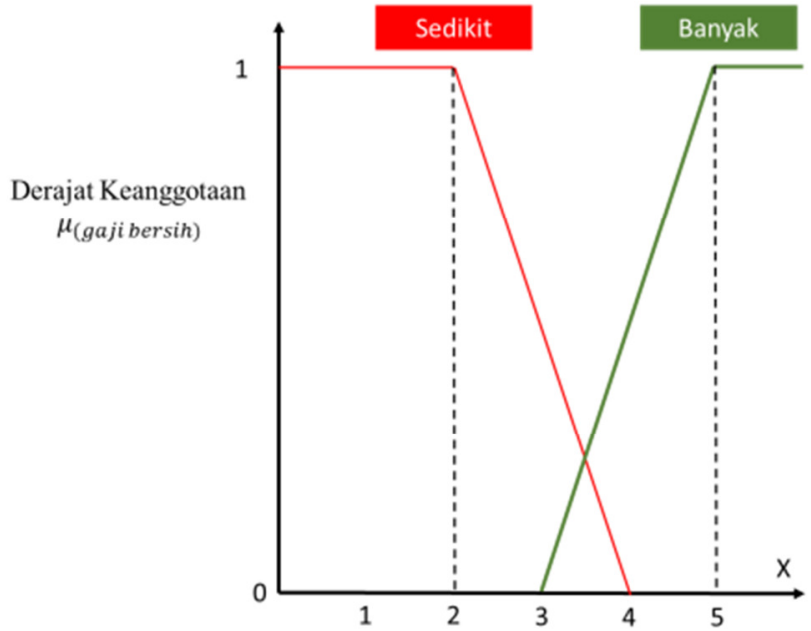

Gambar 4. Kurva Gaji Bersih

$$
\begin{aligned}
& \mu_{\text {sedikit }(\text { gaji bersih })}=\left\{\begin{array}{cc}
0, & x \geq 4 \\
\frac{4-x}{2}, & 2<x<4 \\
1, & x \leq 2
\end{array}\right. \\
& \mu_{\text {banyak }}(\text { gaji bersih })=\left\{\begin{array}{cc}
0, & x \leq 3 \\
\frac{x-3}{2}, & 3<x<5 \\
1, & x \geq 5
\end{array}\right.
\end{aligned}
$$

Sedangkan untuk fuzzifikasi variabel output dengan derajat keanggotaa dan kurva bahu sebagai berikut:

1. Fuzzifikasi variabel bonus gaji didapatkan dari kurva pada gambar 5 berikut.

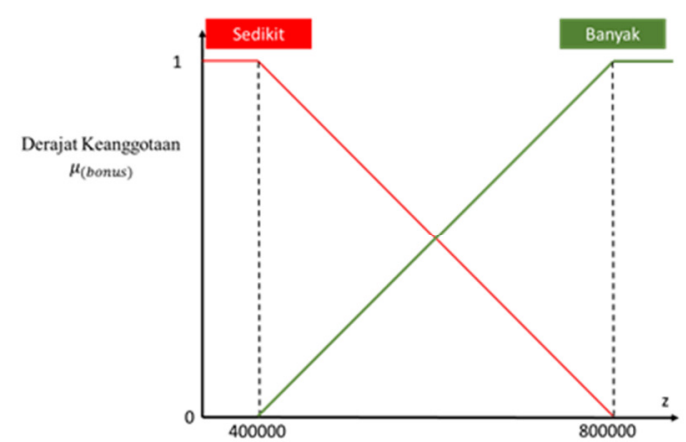

Gambar 5 Kurva Bonus Gaji

Julianto, et.,al [Rancang Bangun Sistem Informasi Penggajian Karyawan Menggunakan Metode Fuzzy Tsukamoto] 


$$
\begin{gathered}
\mu_{\text {sedikit }} \text { (bonus gaji) }=\left\{\begin{array}{cc}
0, & x \geq 800000 \\
\frac{800000-x}{400000}, & 400000<x<800000 \\
1, & x \leq 400000
\end{array}\right. \\
\mu_{\text {banyak } \text { (bonus gaji) }}=\left\{\begin{array}{cc}
1, & x \geq 800000 \\
\frac{x-400000}{800000}, & 400000<x<800000 \\
0, & x \leq 400000
\end{array}\right.
\end{gathered}
$$

\subsection{Fuzzy Inference System Rules}

Setelah melalui perhitungan seluruh nilai yang tedapat dalam keanggotaan fuzzy diinferensikan terhadap aturan-aturan fuzzy (rules)[8]. Terkandung 2 nilai masukan (t) dan 1 nilai keluaran yang perlu diterapkan terhadap fuzzy rules. Untuk menentukan nilai keluaran berupa bonus gaji yang diberikan kepada karyawan, ada 6 aturan yang digunakan yaitu:

[R1] IF Masa Kerja Baru AND Gaji Bersih Sedikit THEN Bonus Sedikit

[R2] IF Masa Kerja Baru AND Gaji Bersih Banyak THEN Bonus Sedikit

[R3] IF Masa Kerja Sedang AND Gaji Bersih Sedikit THEN Bonus Sedikit

[R4] IF Masa Kerja Sedang AND Gaji Bersih Banyak THEN Bonus Banyak

[R5] IF Masa Kerja Lama AND Gaji Bersih Sedikit THEN Bonus Banyak

[R6] IF Masa Kerja Lama AND Gaji Bersih Banyak THEN Bonus Banyak

\subsection{Deffuzifikasi}

Defuzzifikasi mewujudkan tahapan mengubah nilai rasio yang berbentuk derajat keanggotaan keluaran ( $\alpha$ - predikat) jadi variabel numeric kembali (crisp). Jika defuzzy memiliki nilai 0 maka diabaikan, karena tidak berpengaruh dalam perhitungan selanjutnya[2].

\subsection{Respresentasi Nilai}

Penelitian ini menggunakan data karyawan PT.Olew Plasindo Jaya Makmur, data yang diperoleh disesuaikan dengan kriteria-kriteria yang dibutuhkan seperti masa kerja karyawan dan gaji bersih karyawan. Data yang digunakan sebanyak 30 data karyawan seperti gambar 6 berikut. 


\section{PT. OLEW PLASINDO JAYA MAKMUR}

PLASTIC CONTAINERS FOR COSMETICS

Ji. Raya Tapos RT.002 mW OO3 Kel Tapos Keo Tapos Kota Depok

No.TeqMFax : 021 -75904014 E-Mall : olewplasindojayaeryahoo.com

Data Karyawan Per Bulan Naret 2021

\begin{tabular}{|c|c|c|c|}
\hline NO & NAMA KARYAWAN & Tahun Mulai Kerja & Gaji Bersih \\
\hline 1 & YUNIAR & 2012 & $\operatorname{Rp} 5.100 .000$ \\
\hline 2 & MITA AYU ASTAMI & 2017 & Rp 3.750.000 \\
\hline 3 & SAUMUDIN & 2014 & Rp5.100.000 \\
\hline 4 & AI NUROHIMAH & 2015 & Rp5.100.000 \\
\hline 5 & EVI & 2016 & $\operatorname{Rp} 3.800,000$ \\
\hline 6 & IISNA NURAISAH & 2015 & Rp 5.000 .000 \\
\hline 7 & AMRINA ROSYADAN & 2015 & Rp5.100.000 \\
\hline 8 & DADI SUHENDAR & 2015 & $\operatorname{Rp} 4.800 .000$ \\
\hline 9 & ADRI YANUSMOY & 2016 & $R p 3.800,000$ \\
\hline 10 & AHMMO KODIR & 2016 & Rp 3.800.000 \\
\hline 11 & SUWENO & 2016 & $\operatorname{Rp} 3.800 .000$ \\
\hline 12 & NOVI KOMASARI & 2016 & $\operatorname{Rp} 3.800 .000$ \\
\hline 13 & NYADI LUGTO & 2016 & Rp $3.800,000$ \\
\hline 14 & PIKA NURMALA & 2017 & $\operatorname{Rp} 3.800 .000$ \\
\hline 15 & IRPAN SUTISNA & 2017 & Rp 3.800 .000 \\
\hline 16 & KHASANAHWATI & 2017 & $\operatorname{Rp} 3.800 .000$ \\
\hline 17 & SURYAMAN & 2017 & Rp 3.700 .000 \\
\hline 18 & MAMAN & 2017 & $\operatorname{Rp} 3.800 .000$ \\
\hline 19 & SANDI GUNAWAN & 2018 & $\operatorname{Rp} 3.800000$ \\
\hline 20 & MARYAT & 2018 & $\operatorname{Rp} 3.800 .000$ \\
\hline 21 & DEDI RAHARO & 2018 & $\operatorname{Rp} 3.800 .000$ \\
\hline 22 & RSATU AQOBAH & 2018 & $\operatorname{Rp} 3.750 .000$ \\
\hline 23 & A HWRUL GUNAWAN & 2018 & Rp 3.750.000 \\
\hline 24 & RIKI WIRAYUDA & 2018 & $\operatorname{Rp} 3.800 .000$ \\
\hline 25 & CHOIRUL SYAHRONI & 2018 & Rp 3.800 .000 \\
\hline 26 & SURYA HADI IRAWAN & 2018 & $\operatorname{Rp} 3.800000$ \\
\hline 27 & WAWAN HERMAWAN & 2018 & Rp 3.800.000 \\
\hline 28 & SII MASITOH & 2018 & $\operatorname{Rp} 3.800 .000$ \\
\hline 29 & Winda Efriani & 2018 & Rp 3.800 .000 \\
\hline 30 & Yandi Mulyadi & 2019 & Rp 3.750.000 \\
\hline
\end{tabular}

Dikeahui Oleh

Depok, 28 Marc1 2021

Dibuat Olch

$\frac{\text { II. Edi Warpene S.LI }}{\text { Direknur Perucahaan }}$

Yana

IIRD

Gambar 6. Data Karyawan Per Maret 2021

Dari data diatas akan dilakukan perhitungan dengan memasukan data satu persatu kedalam fungsi derajat keanggotaan yang ada kemudian digunakan rules yang ditetapkan untuk kemudian mencari deffuzifikasi yang didapat dari masing-masing karyawan.

Contoh perhitungan:

Perhitungan data pertama atas nama Yuniar, dilihat dari gambar 6 mulai bekerja dari tahun 2012 berarti hingga tahun ini 2021 berarti sudah bekerja selama 9 tahun. Kemudian gaji bersih yang didapatkan pada bulan Maret sesuai data adalah Rp.5.100.000,- jadi penyelesaiannya adalah sebagai berikut: 
Diketahui:

Jumlah masa kerja $=9$ tahun

Jumlah gaji bersih $=$ Rp.5.100.000,-

Penyelesaian menggunakan metode Tsukamoto yaitu:

Proses pertama yaitu fuzzifikasi.

1. Masa kerja; menggunakan 3 fungsi keanggotaan fuzzy, yakni BARU, SEDANG, dan LAMA ( gambar 3). Derajat keanggotaan untuk masa kerja 9 tahun adalah:

$$
\begin{aligned}
\mu_{\text {baru }}(9) & =x \geq 5 \\
& =9 \geq 5 \\
& =0 \\
\mu_{\text {sedang }}(9) & =x \leq 3 \text { atau } x \geq 7 \\
& =9 \leq 3 \text { atau } 9 \geq 7 \\
& =0 \\
\mu_{\text {lama }}(9) & =x \geq 8 \\
& =9 \geq 8 \\
& =1
\end{aligned}
$$

2. Gaji bersih; berisikan 2 sungsi keanggotaan fuzzy, yaitu SEDIKIT dan BANYAK ( gambar

4). Derajat keanggotaan untuk gaji bersih 5.100 .000 atau 5,1 adalah:

$$
\begin{gathered}
\mu_{\text {sedikit }}(5,1)=x \geq 4 \\
=5,1 \geq 4 \\
=0 \\
\mu_{\text {banyak }}(5,1)=x \geq 5 \\
=5,1 \geq 5 \\
=1
\end{gathered}
$$

Setalah mengetahui semua variabel, selanjutnya menentukan nilai z untuk setiap aturan.

[R1] IF Masa Kerja Baru AND Gaji Bersih Sedikit THEN Bonus Sedikit

a-predikat $1=\mu$ masa kerja baru $\cap \mu$ gaji bersih sedikit

$=\min (0 ; 0)$

$=\min 0$

Himpunan Bonus Sedikit

$$
\begin{aligned}
\mathrm{z} 1 & =(800000-\mathrm{z}) / 400000=0 \\
& =800000-(0 * 400000)=800000 \\
& =800000
\end{aligned}
$$

[R2] IF Masa Kerja Baru AND Gaji Bersih Banyak THEN Bonus Sedikit

a-predikat $2=\mu$ masa kerja baru $\cap \mu$ gaji bersih banyak

$$
\begin{aligned}
& =\min (0 ; 1) \\
& =\min 0
\end{aligned}
$$

Himpunan Bonus Sedikit

$$
\begin{aligned}
\mathrm{z} 2 & =(800000-\mathrm{z}) / 400000=0 \\
& =800000-(0 * 400000)=800000 \\
& =800000
\end{aligned}
$$

[R3] IF Masa Kerja Sedang AND Gaji Bersih Sedikit THEN Bonus Sedikit

a-predikat $3=\mu$ masa kerja sedang $\cap \mu$ gaji bersih sedikit

$$
\begin{aligned}
& =\min (0 ; 0) \\
& =\min 0
\end{aligned}
$$

Himpunan Bonus Sedikit

$$
\text { z3 }
$$

$$
\begin{aligned}
& =(800000-\mathrm{z}) / 400000=0 \\
& =800000-(0 * 400000)=800000 \\
& =800000
\end{aligned}
$$


[R4] IF Masa Kerja Sedang AND Gaji Bersih Banyak THEN Bonus Banyak

a-predikat $4=\mu$ masa kerja sedang $\cap \mu$ gaji bersih banyak

$$
\begin{aligned}
& =\min (0 ; 1) \\
& =\min 0
\end{aligned}
$$

Himpunan Bonus Banyak

$$
\begin{aligned}
\mathrm{z} 4 & =(\mathrm{z}-400000) / 400000=0 \\
& =400000+(0 * 400000)=400000 \\
& =400000
\end{aligned}
$$

[R5] IF Masa Kerja Lama AND Gaji Bersih Sedikit THEN Bonus Banyak

a-predikat $5=\mu$ masa kerja lama $\cap \mu$ gaji bersih sedikit

$$
=\min (0 ; 0)
$$$$
=\min 0
$$

Himpunan Bonus Banyak

$$
\mathrm{z5} \quad \begin{aligned}
& =(\mathrm{z}-400000) / 400000=0 \\
& =400000+(0 * 400000)=400000 \\
& =400000
\end{aligned}
$$

[R6] IF Masa Kerja Lama AND Gaji Bersih Banyak THEN Bonus Banyak

a-predikat $6=\mu$ masa kerja lama $\cap \mu$ gaji bersih banyak

$$
\begin{aligned}
& =\min (1 ; 1) \\
& =\min 1
\end{aligned}
$$

Himpunan Bonus Banyak

$$
\begin{aligned}
\mathrm{z6} & =(\mathrm{z}-400000) / 400000=1 \\
& =400000+(1 * 400000)=400000 \\
& =800000
\end{aligned}
$$

Setalah nilai z setiap himpunan ditemukan, maka dapat dicari selanjutnya berapah nilai z, rumus nilai $\mathrm{z}$ adalah sebagai berikut:

$$
\mathrm{Z}=\frac{\text { apend } 1 * z 1+\text { apend } 2 * z 2}{\text { apend } 1+\text { apend } 2}
$$

Untuk Z masih dengan nama Yuniar adalah sebagai berikut:

$$
\begin{gathered}
Z=\frac{\text { apend } 1 * Z 1+\text { apend } 2 * Z 2+\text { apend } 3 * Z 3+\text { apend } 4 * Z 4+\text { apend } 5 * Z 5+\text { apend } 6 * Z 6}{\text { apend } 1+\text { apend } 2+\text { apend } 3+\text { apend } 4+\text { apend } 5+\text { apend } 6} \\
Z=\frac{0 * 800000+0 * 800000+0 * 800000+0 * 400000+0 * 400000+1 * 800000}{0+0+0+0+0+1} \\
Z=\frac{800000}{1}=800000
\end{gathered}
$$

Jadi jumlah bonus yang diterima karyawan dengan nama Yuniar adalah 800.000 berarti bonus hasilnya Banyak.

\subsection{Hasil Pengujian}

Hasil dari keseluruhan perhitungan nilai bonus, dengan masing-masing kriteria dari data karyawan yang ada dapat dilihat pada Tabel 1 . 
Tabel 1. Hasil Perhitungan Keseluruhan Nilai Bonus

\begin{tabular}{|c|l|r|r|r|l|}
\hline No & kriteria & $\begin{array}{r}\text { Masa } \\
\text { Kerja } \\
\text { (tahun) }\end{array}$ & $\begin{array}{c}\text { Gaji } \\
\text { Bersih } \\
\text { (juta) }\end{array}$ & NILAI & HASIL \\
\hline 1 & YUNIAR & 9 & 5,10 & 800000 & BANYAK \\
\hline 2 & MITA AYU ASTAMI & 4 & 3,75 & 537943,3 & BANYAK \\
\hline 3 & SALIMUDIN & 7 & 5,10 & 533333,3 & BANYAK \\
\hline 4 & AI NUROHIMAH & 6 & 5,10 & 626666,7 & BANYAK \\
\hline 5 & EVI & 5 & 3,80 & 664000 & BANYAK \\
\hline 6 & LISNA NURAISAH & 6 & 5,00 & 626666,7 & BANYAK \\
\hline 7 & AMRINA ROSYADAN & 6 & 5,10 & 626666,7 & BANYAK \\
\hline 8 & DADI SUHENDAR & 6 & 4,80 & 626666,7 & BANYAK \\
\hline 9 & ADRI YANUSMOY & 5 & 3,80 & 664000 & BANYAK \\
\hline 10 & AHMAD KODIR & 5 & 3,80 & 664000 & BANYAK \\
\hline 11 & SUWENO & 5 & 3,80 & 664000 & BANYAK \\
\hline 12 & NOVI KOMASARI & 5 & 3,80 & 664000 & BANYAK \\
\hline 13 & NYADI LUGITO & 5 & 3,80 & 664000 & BANYAK \\
\hline 14 & PIKA NURMALA & 4 & 3,80 & 675238,1 & BANYAK \\
\hline 15 & IRPAN SUTISNA & 4 & 3,80 & 675238,1 & BANYAK \\
\hline 16 & KHASANAH WATI & 4 & 3,80 & 675238,1 & BANYAK \\
\hline 17 & SURYAMAN & 4 & 3,70 & 686666,7 & BANYAK \\
\hline 18 & MAMAN & 4 & 3,80 & 675238,1 & BANYAK \\
\hline 19 & SANDI GUNAWAN & 3 & 3,80 & 664000 & BANYAK \\
\hline 20 & MARYATI & 3 & 3,80 & 664000 & BANYAK \\
\hline 21 & DEDI RAHARJO & 3 & 3,80 & 664000 & BANYAK \\
\hline 22 & RISATUL AQOBAH & 3 & 3,75 & 675000 & BANYAK \\
\hline 23 & A HAIRUL GUNAWAN & 3 & 3,75 & 675000 & BANYAK \\
\hline 24 & RIKI WIRAYUDA & 3 & 3,80 & 664000 & BANYAK \\
\hline 25 & CHOIRUL SYAHRONI & 3 & 3,80 & 664000 & BANYAK \\
\hline 26 & SURYA HADI IRAWAN & 3 & 3,80 & 664000 & BANYAK \\
\hline 27 & WAWAN HERMAWAN & 3 & 3,80 & 664000 & BANYAK \\
\hline 28 & SITI MASITOH & 3 & 3,80 & 664000 & BANYAK \\
\hline 29 & WINDA EFRIANI & 3 & 3,80 & 664000 & BANYAK \\
\hline 30 & YANDI MULYADI & 2 & 3,75 & 675000 & BANYAK \\
\hline & & & & & \\
\hline
\end{tabular}

\section{KESIMPULAN}

Dari pemaparan bahasan diatas, diperoleh sebuah kesimpulan yang peneliti dapat sampaikan antara lain: Metode Tsukamoto menggunakan analisa terhadap data karyawan menggunakan proses-proses yakni seperti menetapkan fungsi keanggotaan dari masing-masing variabel masa kerja dan gaji bersih, kemudian membuat aturan atau inferensi nilai masukan (masa kerja dan gaji bersih) dan keluaran (hasil), tahap berikutnya melakukan deffuzifikasi untuk mendapatkan hasil akhir.

Keluaran yang dihasilkan adalah berupa nilai dan hasil untuk kemudian bonus yang didapatkan tergolong sedikit atau banyak. Besaran bonus gaji yang didapatkan karyawan sangat bervariatif bergantung dari rules yang ditetapkan dan kriteria masukkan yang ada. 


\section{SARAN}

Untuk saran yang dapat penulis sampaikan sebagai informasi terhadap pengembangan penelitian selanjutnya adalah menggunakan data seluruh karyawan PT.Olew Plasindo Jaya Makmur untuk mengetahui keakuratan metode fuzzy Tsukamoto dalam mengetahui nilai bonus seluruh karyawan. Dapat pula dikembangkan dengan kombinasi metode lain untuk membandingkan metode yang lebih efektif, metode lain itu antara lain adalah metode fuzzy Mamdani dan metode fuzzy Sugeno.

\section{UCAPAN TERIMA KASIH}

Dalam melakukan penelitian ini tidak lupa penulis berterima kasih kepada Bapak H. Edi Warseno S.E selaku pimpinan PT.Olew Plasindo Jaya Makmur dalam memberikan izin menggunakan keperluan data-data perusahaan untuk penelitian, kemudian untuk Universitas Nasional selaku institusi tempat peneliti mempelajari ilmu Teknik Informatika, serta Ibu Dr. Septi Andryana, S.Kom., MMSI dan Ibu Aris Gunaryati, S.Si., MMSI sebagai dosen pembimbing yang telah membimbing penulis sampai akhir.

\section{DAFTAR PUSTAKA}

[1] A. Moenir and F. Yuliyanto, 2017, "Perancangan Sistem Informasi Penggajian Berbasis Web Dengan Metode Waterfall pada PT. Sinar Metrindo Perkasa (Simetri),” J. Inform. Univ. Pamulang, Vol. 2, No. 3, p. 127, doi: 10.32493/informatika.v2i3.1237.

[2] R. Rizaldi, "Analisis Pemilihan Karyawan Teladan Menggunakan Metode Fuzzy Tsukamoto pada PT. Harian Haluan Sumbar Mandiri,” Vol. 1, No. September, pp. 321326, 2018, [Online]. Available: https://jurnal.stmikroyal.ac.id/index.php/senar/article/view/195.

[3] A. Zaki and H. A. Santoso, 2016, "Model Fuzzy Tsukamoto Untuk Klasifikasi Dalam Prediksi Krisis Energi di Indonesia," Creat. Inf. Technol. J., Vol. 3, No. 3, p. 185, doi: 10.24076/citec.2016v3i3.76.

[4] R. S. Armanda and W. F. Mahmudy, 2016, "Penerapan Algoritma Genetika Untuk Penentuan Batasan Fungsi Kenggotaan Fuzzy Tsukamoto pada Kasus Peramalan Permintaan Barang," J. Teknol. Inf. dan Ilmu Komput., Vol. 3, No. 3, p. 169, doi: 10.25126/jtiik.201633201.

[5] M. Santa and D. Jollyta, 2020. "Penerapan Fuzzy Tsukamoto pada Sistem Pendukung Keputusan : Sistem Monitoring Puswil,” J. Mhs. Apl. Teknol. Komput. dan Inf., Vol. 2, No. 2, pp. 83-90,

[6] Elisawati, 2017, "Sistem Deteksi Objek Dengan Menggunakan Sensor Ultrasonik Berbasis Fuzzy,” J. Inform. Manaj. Dan Komput., Vol. 9, No. 1, pp. 10-14, [Online]. Available: http://ejournal.stmikdumai.ac.id/Index.Ph\%0Ap/Path/Article/View/58.

[7] S. M. Farouq, Kemal, 2014. "Jurnal Teknik, Vol 6 No 2 September 2014," Penerapan Fuzzy Tsukamoto Dalam Pengangkatan Jab. Pegawai Di Bkd Lamongan, Vol. 6, No. 2, pp. 577-584, 
Jatisi

ISSN 2407-4322

Vol. 8, No. 4, Desember 2021, Hal. 1710-1722

E- ISSN 2503-2933

1722

[8] N. R. Sari and W. F. Mahmudy, 2015. "Fuzzy Inference System Tsukamoto Untuk Menentukan Kelayakan Calon Pegawai,” Semin. Nas. Sist. Inf. Indones., No. November, pp. 245-252,

Julianto, et.,al [Rancang Bangun Sistem Informasi Penggajian Karyawan Menggunakan Metode Fuzzy Tsukamoto] 